\title{
Novel Functional Motifs of the Cell Entry Glycoprotein D for Oncolytic Herpes Simplex Viruses
}

\author{
Boxu Ren 1,2*\#, Xiaoqin Liu1,3,4\#, Yingying Wang1,3,4\#, Yanning Lyu5 , Hongyi Xin6, \\ Xiaochun Peng $1,3,7$, Ying Xiang1,3,4, Xianwang Wang1,3,6*, Hongwu Xin 1,3,4* \\ ${ }^{1}$ The Second School of Clinical Medicine, Health Science Center, Yangtze University, Jingzhou, China \\ ${ }^{2}$ Department of Nursing and Medical Imaging Technology, Yangtze University, Jingzhou, China \\ ${ }^{3}$ Laboratory of Oncology, Center for Molecular Medicine, School of Basic Medicine, Health Science Center, Yangtze University, \\ Jingzhou, China \\ ${ }^{4}$ Department of Biochemistry and Molecular Biology, School of Basic Medicine, Health Science Center, Yangtze University, \\ Jingzhou, China \\ ${ }^{5}$ Institute for Infectious Diseases and Endemic Diseases Prevention and Control, Beijing Center for Diseases Prevention and \\ Control, Beijing, China \\ ${ }^{6}$ Animal Health Biotechnology, Temasek Life Sciences Laboratory, National University of Singapore, Singapore \\ ${ }^{7}$ Department of Pathophysiology, School of Basic Medicine, Health Science Center, Yangtze University, Jingzhou, China \\ Email: ‘boxuren188@163.com, ^275379987@qq.com, ${ }^{\star}$ hongwu_xin@126.com
}

How to cite this paper: Ren, B.X., Liu, Z.Q., Wang, Y.Y., Lyu, Y.N., Xin, H.Y., Peng, X.C., Xiang, Y., Wang, X.W. and Xin, H.W. (2021) Novel Functional Motifs of the Cell Entry Glycoprotein D for Oncolytic Herpes Simplex Viruses. Yangtze Medicine, 5, 266-286.

https://doi.org/10.4236/ym.2021.54025

Received: June 30, 2021

Accepted: December 25, 2021

Published: December 28, 2021

Copyright (c) 2021 by author(s) and Scientific Research Publishing Inc. This work is licensed under the Creative Commons Attribution International License (CC BY 4.0).

http://creativecommons.org/licenses/by/4.0/

\begin{abstract}
Background: Oncolytic herpes simplex virus (oHSV) have been proved effective and safe to treat tumors. Glycoprotein $\mathrm{D}(\mathrm{gD})$ has been engineered for targeting cancer cells and de-targeting normal cells successfully, however, the effectiveness and safety of oHSVs still need to be improved. Method: Here we sequenced the DNA encoding gD of our recently isolated new strain HSV-1-LXMW and compared the gD amino acid sequence with the gDs of other 7 HSV-1 and 3 HSV-2 strains. Results: Phylogenetic analysis revealed that HSV-1-LXMW is evolutionarily close to HSV-1-Patton and -KOS strains. The gD amino acid sequence alignment identified 19 conserved and 8 variable regions. We further predicted 10 new motifs in HSV gD for the first time and identified motif differences in HSV-1 and HSV-2. We summarized the gD-engineered oHSVs and found that some of the newly identified gD motifs are actually functional. Conclusion: Our results shed light on HSV gD biology and provided new directions for future $\mathrm{gD}$ functional studies and engineering in order to make better oHSVs.
\end{abstract}

\section{Keywords}

Oncolytic Herpes Simplex Virus (oHSV), Amino Acids (AA), Glycoprotein D (gD), Cancer Treatment, Reengineering Virus

\footnotetext{
${ }^{\star}$ Corresponding authors.

"Boxu Ren, Xiaoqin Liu and Yingying Wang contributed equally to this work.
} 


\section{Background}

Tumors contain heterogeneous cancer cells, such as tumor stem cells, and tumor stromal cells, immune cells in the tumor microenvironment [1]-[6]. The infection of herpes simplex virus 1 and 2 (HSV-1 and -2) is spread worldwide. The infection of HSV-1 often causes oral lesion and is frequently diagnosed in children, while the HSV-2 causes genital lesion and sexually transmitted diseases [7]. HSV in not only a human pathogen, but HSV mutants named oncolytic herpes simplex virus (oHSV) can be used to treat cancer [8] [9] [10]. Because the infection of HSV can induce rapid and efficient cell killing, HSVs have a wide host range, and the virus replication and infection can be controlled by effective anti-herpetic agents, HSVs have been widely used as oHSVs [11]-[18]. Targeting cancer cells without infecting normal cells is still a big challenge in cancer treatment [19]. Oncolytic viruses provided a new way to retarget to the specific cancer cells [20]. For example, Jeeninga et al. used the characteristics that human immunodeficiency virus 1 (HIV-1) infects T lymphocytes specifically to construct HIV-1 derived oncolytic viruses to treat the T-cell acute lymphoblastic leukemia (T-ALL) [21]. Schneider et al. engineered measles virus to enter cells expressing specific receptors for epidermal growth factor or the insulin-like growth factor 1 , and trigger cell death [22]. T-VEC is engineered by deletion of the genes $\gamma 34.5$ and US11 (ICP47) and insertion of the gene encoding human granulocyte macrophage colony-stimulating factor (GM-CSF) [15]. In 2015, the US Food and Drug Administration (FDA) proved that T-VEC as the first oHSV to treat advanced inoperable malignant melanoma [16]. HSV envelope glycoproteins were also engineered to target the special receptors expressed on tumor cells [23].

The process of virus entering into the host cells includes recognition of virus receptors, triggering the fusion process and fusion execution [24]. This process needs the glycoprotein D (gD), heterodimer glycoprotein H/glycoprotein L (gH/gL) and glycoprotein B (gB), as well as their cognate receptors [25] [26] [27] [28] (Figure $1(\mathrm{~A})$ ). gD is a glycoprotein that can interact with one of its three receptors, herpes virus entry mediator (HVEM), nectin-1, and 3-O-sulfated heparan sulfate (3-OS HS), thus inducing the initiation of entry process [29]-[34]. Receptor binding leads to the conformational change of $\mathrm{gD}$, which will trigger the virus fusion process after activation of the heterodimer $\mathrm{gH} / \mathrm{gL}$ and $\mathrm{gB}$ [35] (Figure $1(\mathrm{~A})$ ), thus $\mathrm{gD}$ is the major tropism determinant.

The gD protein has been divided into three parts, including the extracellular, transmembrane and cytoplasmic domains [36] [37] [38]. gD is made up of 394 AA and becomes a mature form (369 AA) after cleavage of the 25 AA signal sequence at the $\mathrm{N}$-terminal and the transmembrane domain is between AA 317 and 339 [39]. The gD co-crystal structure revealed that the HVEM binding site in the $\mathrm{gD}$ is located at amino acids 1 - 37 [40]. The nectin-1 biding site is discontinuous, and the critical residues have been identified at AA 34, 38, 215, 222, and 223 [41] [42] [43]. The N-terminus (residues 1 - 260) contains the receptors 
A
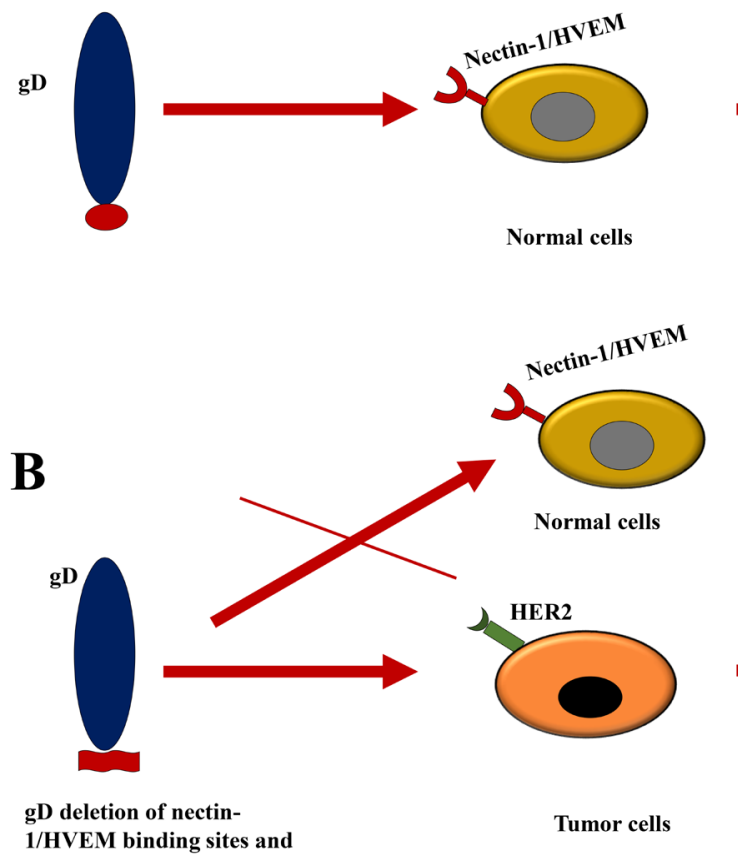

1/HVEM binding sites and
WT HSV

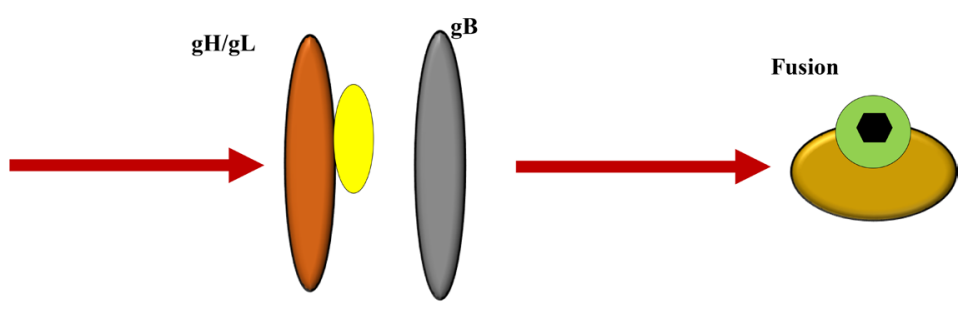

gD retargeted oHSV

added the scFv to HER2
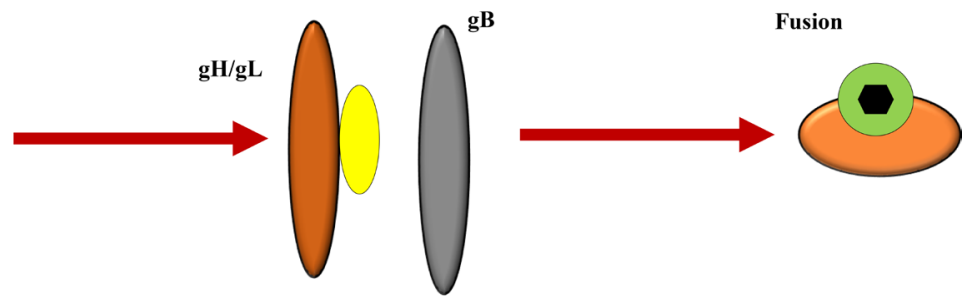

Figure 1. Wild type (A) or gD retargeted (B) HSV enters the cell.

binding sites, while the C-terminus (residues 260 - 310) acts as the pro-fusion domain (PFD) that can be used to induce virus infectivity and fusion process [44]. A quantity of mutations in gD can abolish the binding of HVEM and 3-OS HS with $\mathrm{gD}$ at the same time, so these two receptors binding sites in $\mathrm{gD}$ are at least overlapping in part [45]. However, several mutations aborted the HVEM binding to the gD but not nectin-1, so the nectin-1 binding site is discrete from HVEM but partially overlapping, and its location is downstream of residue 32 [36] [41] [43] [45] [46] [47] [48]. The interaction of gD with HVEM or nectin-1 can lead to displacement of the binding of C-terminus and N-terminus, then lead to the structural change of gD [44] [49]. In the process of virus entry into host cells, AA 61-218 don't code executable meanings and the interaction of the ligand with its receptor doesn't need to change the structure of gD [50]. Consistent with reports, mutations the amino acids between 25 - 27 can abolish the binding of gD with HVEM and increase the affinity of gD with ncctin-1 [33] [45] [51].

The majority of oHSV given through systemic route were cleared by neutralization antibodies and other immune effects [52]. The intralesional injection of oHSV limited the oHSV usage in clinics. The effectiveness and safety of oHSV still need to be improved. Here we sequenced the DNA encoding gD of our recently isolated new strain HSV-1-LXMW, compared the gD amino acid sequence with the other $10 \mathrm{gDs}$ by phylogenetic analysis, amino acid sequence alignment, and motif predictions. Our results shed light on HSV gD biology and provided new options for future engineering of $\mathrm{gD}$ in order to make improved 
oHSVs.

\section{Materials and Methods}

\subsection{HSV Genomic DNA Sequencing Analysis}

A new HSV strain from an oral herpes lesion of a patient in Beijing, named as HSV strain LXMW, was isolated earlier [53]. The HSV DNA sequence identification was carried out by genomic DNA sequencing as described earlier [53]. Briefly, we isolated HSV DNA in our laboratory, high-quality genomic DNA (500 ng) was submitted to Beijing Genomics Institute (BGI, http://www.genomics.cn) for sequence analysis and Burrows-Wheeler Aligner (BWA) software was used for alignment. The genomic sequences of other $10 \mathrm{HSV}$ strains were obtained from NCBI Reference Database (Table 1).

\subsection{Phylogenetic Analysis of the gD Amino Acids in HSV-1 and HSV-2}

For phylogenetic analysis of the gD amino acid sequences of $11 \mathrm{HSV}$ strains, the software MEGA7 was used. The evolutionary history was calculated by means of the Maximum Likelihood method option based on the General Time Reversible model with "completely deletion". The bootstrap consensus tree is taken to represent the evolutionary history of the taxa analyzed. Branches corresponding to partitions reproduced in less than $50 \%$ bootstrap replicates are collapsed. Initial tree(s) for the heuristic search were obtained automatically by applying Neighbor-Join and BioNJ algorithms to a matrix of pair wise distances estimated using the Maximum Composite Likelihood (MCL) approach, and then selecting

Table 1. HSV strains studied in this article.

\begin{tabular}{lccccc}
\hline HSV Strain & $\begin{array}{c}\text { Gene Bank } \\
\text { ID }\end{array}$ & Tax-ID & Sub-Date & gD DNA sequence & University, Country \\
\hline HSV-1 strain LXMW & & & & $138401-139585$ & $\begin{array}{l}\text { Yangtze University, Jingzhou, } \\
\text { China }\end{array}$ \\
HSV-1 strain 17 & JN555585.1 & 10299 & $2011-08-02$ & $138313-141052$ & Glasgow University, UK \\
HSV-1 strain H129 & GU734772.1 & 744249 & $2010-2-9$ & $138193-140911$ & Princeton University, USA \\
HSV-1 strain RH2 & AB618031.1 & 946522 & $2011-2-28$ & $136619-137803$ & Osaka University, Japan \\
HSV-1 isolate SC16 & KX946970.1 & 10309 & $2016-10-30$ & $138699-141443$ & Severo Ochoa, Spain \\
HSV-1 strain Patton isolate & MF959544.1 & 10308 & $2017-10-11$ & $138199-140937$ & NYU, New York, USA \\
HSV-1 strain F & GU734771.1 & 10304 & $2010-2-9$ & $138171-140910$ & Princeton University, USA \\
HSV-1 strain KOS & JQ673480.1 & 10306 & $2012-2-14$ & $138279-139463$ & University of Kansas, USA \\
HSV-2 strain SD90e & KF781518.1 & 1177628 & $2013-10-25$ & $140686-141867$ & $\begin{array}{l}\text { Harvard Medical School, Boston, } \\
\text { USA }\end{array}$ \\
HSV-2 strain HG52 & JN561323.2 & 10315 & $2011-08-05$ & $141016-143588$ & University of Glasgow, UK \\
HSV-2 strain G & KU310668.1 & 10314 & $2015-12-16$ & $150357-151400$ & Einstein College, USA \\
\hline
\end{tabular}


the topology with superior log likelihood value.

\subsection{Alignment of gD Amino Acid Sequences of HSV-1 and HSV-2 Strains}

The genomic sequences used for analysis were the same as above. The online software EMBL-EBI (https://www.ebi.ac.uk) was used to align the gD amino acid sequences. Amino acid differences were marked.

\subsection{Prediction of the gD Secondary Structure, Motifs and Function Domains}

The online software UCL-CS Bioinformatics (http://bioinf.cs.ucl.ac.uk/) was used to predict the secondary structure. The stringent conditions were set as default by the online program. The online software Phobius

(https://phobius.sbc.su.se/) was used to predict the gD function domain. We predicted the conserved domain of gD in LXMW using the online software NCBI (https://www.ncbi.nlm.nih.gov), and the motifs were predicted using the online software MEME (http://meme-suite.org/).

\section{Results}

\section{1. gD DNA Sequencing of Our New Strain HSV-1-LXMW}

The sequence of gD was determined as follows: 138401ATGGGGGGGGCTGCC GCCAGGTTGGGGGCCGTGATTTTGTTTGTCGTCATAGTGGGCCTCCAT GGGGTCCGCGGCAAATATGCCTTGGCGGATGCCTCTCTCAAGATGGCC GACCCCAATCGCTTTCGCGGCAAAGACCTTCCGGTCCTGGACCAGCTG ACCGACCCTCCGGGGGTCCGGCGCGTGTACCACATCCAGGCGGGCCTA CCGGACCCGTTCCAGCCCCCCAGCCTCCCGATCACGGTTTACTACGCC GTGTTGGAGCGCGCCTGCCGCAGCGTGCTCCTAAACGCACCGTCGGAG GCCCCCCAGATTGTCCGCGGGGCCTCCGAAGACGTCCGGAAACAACCC TACAACCTGACCATCGCTTGGTTTCGGATGGGAGGCAACTGTGCTATC CCCATCACGGTCATGGAGTACACCGAATGCTCCTACAACAAGTCTCTG GGGGCCTGTCCCATCCGAACGCAGCCCCGCTGGAACTACTATGACAGC TTCAGCGCCGTCAGCGAGGATAACCTGGGGTTCCTGATGCACGCCCCC GCGTTTGAGACCGCCGGCACGTACCTGCGGCTCGTGAAGATAAACGAC TGGACGGAGATTACACAGTTTATCCTGGAGCACCGAGCCAAGGGCTCC TGTAAGTACGCCCTCCCGCTGCGCATCCCCCCGTCAGCCTGCCTCTCCC CCCAGGCCTACCAGCAGGGGGTGACGGTGGACAGCATCGGGATGCTG CCCCGCTTCATCCCCGAGAACCAGCGCACCGTCGCCGTATACAGCTTG AAGATCGCCGGGTGGCACGGGCCCAAGGCCCCATACACGAGCACCCT GCTGCCCCCGGAGCTGTCCGAGACCCCCAACGCCACGCAGCCAGAACT CGCCCCGGAAGACCCCGAGGATTCGGCCCTCTTGGAGGACCCCGTGGG GACGGTGGCGCCGCAAATCCCACCAAACTGGCACATCCCGTCGATCCA GGACGCCGCGACGCCTTACCATCCCCCGGCCACCCCGAACAACATGGG CCTGATCGCCGGCGCGGTGGGCGGCAGTCTCCTGGCAGCCCTGGTCAT 
TTGCGGAATTGTGTACTGGATGCACCGCCGCACTCGGAAAGCCCCAAA GCGCATACGCCTCCCCCACATCCGGGAAGACGACCAGCCGTCCTCGCA CCAGCCCTTGTTTTACTA139585.

\subsection{Translation of HSV-1-LXMW gD DNA Sequence into Amino Acids}

We used the DNAMAN software to translate the DNA sequence to amino acids; the translation result is shown as follow:

MGGAAARLGAVILFVVIVGLHGVRGKYALADASLKMADPNRFRGKDLP VLDQLTDPPGVRRVYHIQAGLPDPFQPPSLPITVYYAVLERACRSVLLNAPS EAPQIVRGASEDVRKQPYNLTIAWFRMGGNCAIPITVMEYTECSYNKSLGA CPIRTQPRWNYYDSFSAVSEDNLGFLMHAPAFETAGTYLRLVKINDWTEIT QFILEHRAKGSCKYALPLRIPPSACLSPQAYQQGVTVDSIGMLPRFIPENQRT VAVYSLKIAGWHGPKAPYTSTLLPPELSETPNATQPELAPEDPEDSALLEDP VGTVAPQIPPNWHIPSIQDAATPYHPPATPNNMGLIAGAVGGSLLAALVIC GIVYWMHRRTRKAPKRIRLPHIREDDQPSSHQPLFY.

\subsection{Phylogenetic Analysis Showed HSV-1-LXMW Is Close to HSV-1-Patton and -KOS}

To understand the evolutionary relationship of our HSV strain with other HSV-1 and HSV-2 strains, a phylogenetic analysis was performed. The gD DNA sequence of HSV-1-LXMW together with 7 HSV-1 strains (17, F, H129, RH2, SC16, Patton and KOS) and 3 HSV-2 strains (G, HG52 and SD90e) (Table 1) were translated to amino acid sequences and analyzed. Our gD is highly similar to HSV-1 strains, but there is no significant similarity between the sequences of our HSV-1-LXMW and other HSV-2 strains. Our data supported that HSV-1LXMW is an HSV-1 strain.

Both the phylogenetic tree data (Figure 2(A)) and neighbor network data (Figure 2(B)) showed the presence of four groups of clustering structures. Our new strain HSV-1-LXMW isolated in Beijing, China is close to strains HSV-1Patton in New York, US and HSV-1-KOS in Princeton, US, and far from the strain HSV-1-17 in University of Kansas, USA (Figure 2). The data showed a mean distance of approximately $87 \%$ among the strains tested collectively.

\subsection{The gD Amino Acid Sequence Alignment Identified 19 Conserved and 8 Variable Regions}

To understand if the gD amino acid sequences are conserved among HSVs and thus likely to be biologically functional, the sequence alignments of the 11 above-described sequences of HSVs were performed (Figure 3). We found that all the HSV-1 gD have 394 amino acids, while there are 393 amino acids in HSV-2 strains SD90e and HG52, and 347 amino acids in HSV-2 strain G (Figure 3). Our results showed that there were fewer mutations among HSV-1 strains in the $\mathrm{gD}$ amino acids sequences, but there are more variations between HSV-1 and HSV-2. Our results identified that there are 2 amino acids of HSV-1-LXMW 
(A)

HSV-1 strain Patton isolate

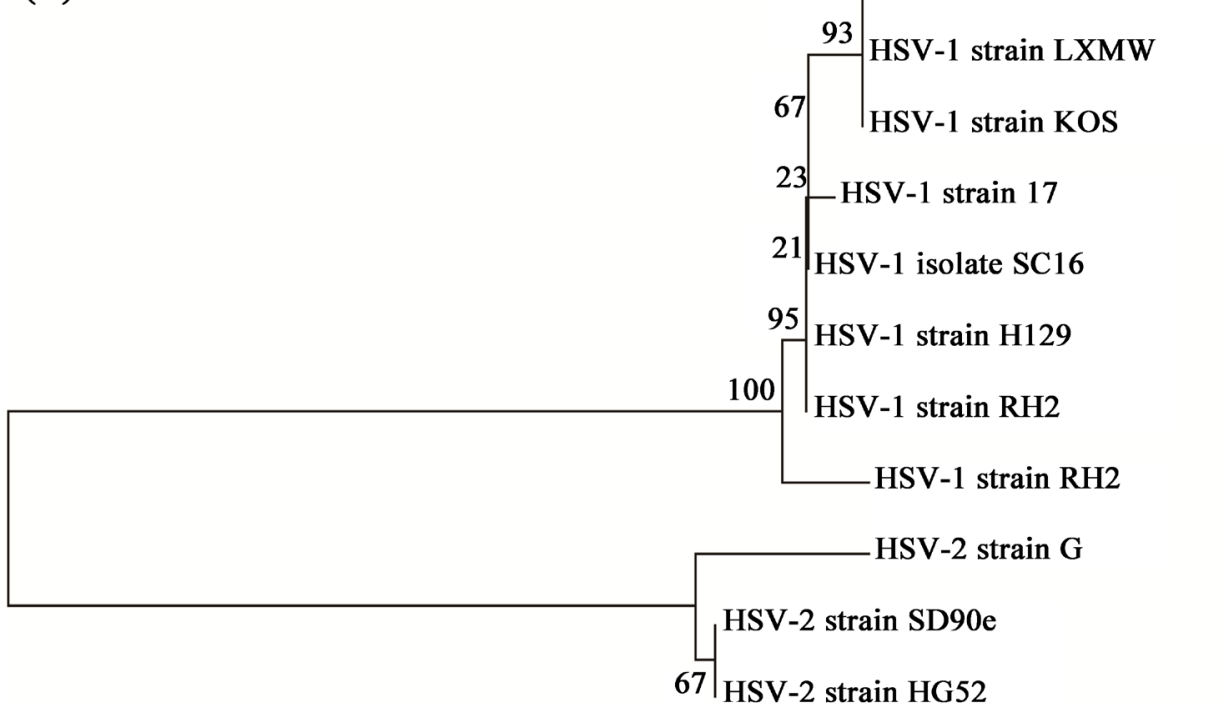

(B)

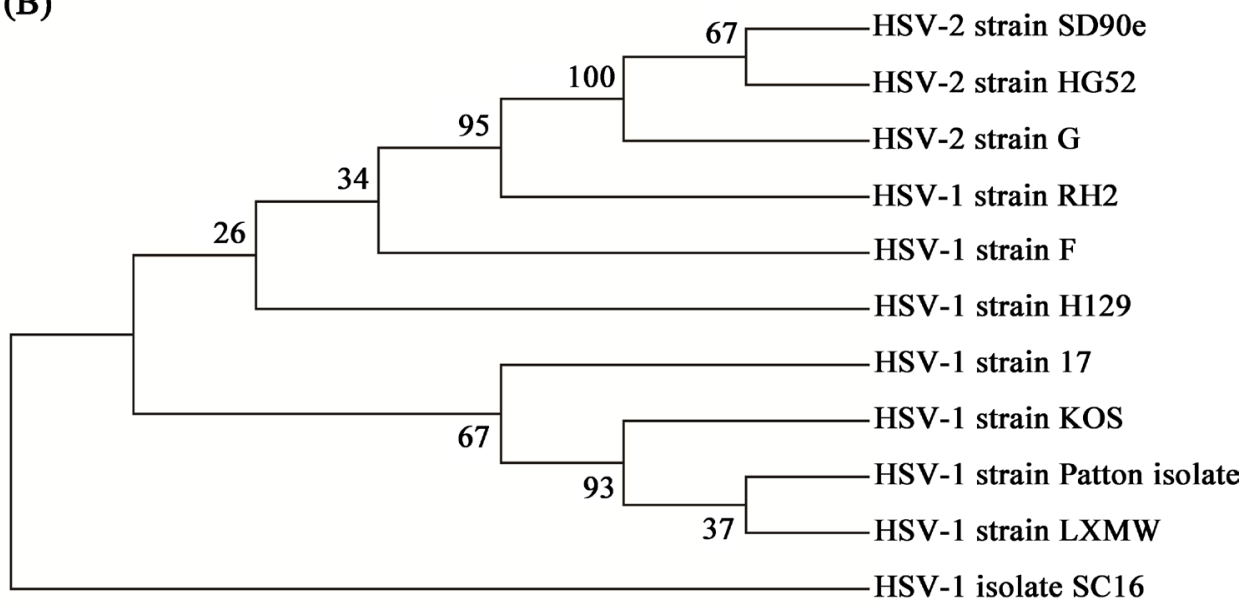

Figure 2. Phylogenetic analysis of HSV-1-LXMW and 10 other HSV strains. The tree was generated by neighbor-joining (NJ) method by means of MEGA7. Trees with the maximum log likelihood are shown. The percentage of trees in which the associated taxa clustered together is shown above the branches. A: The tree is drawn to gage with branch lengths measured in the number of substitutions per site. B: The bootstrap consensus tree is taken to represent the evolutionary history of the taxa analyzed. The phylogenic evolutionary tree discovered that the gD in HSV-1-XLMW was close to HSV-1-Patton and HSV-1-KOS.

(AA 365 and AA 369), HSV-1 strain patron and strain KOS are different from other HSV-1 strains. There are 2 amino acids (AA 25 and AA 367) difference in HSV-1 strain 17 from other HSV-1 strains. There are many amino acids of gD in HSV-2 are different from HSV-1 strains. The gD of HSV-2 strain G is shorter than other HSVs. Both phylogenic analysis and alignment showed that $\mathrm{gD}$ amino acids of LXMW are very similar to HSV-1 strain Pattern and HSV-1 strain KOS. The gD amino acid sequence alignment identified 19 conserved and 8 variable regions (Figure 3). In addition, there is an arginine cluster in HSV-1 


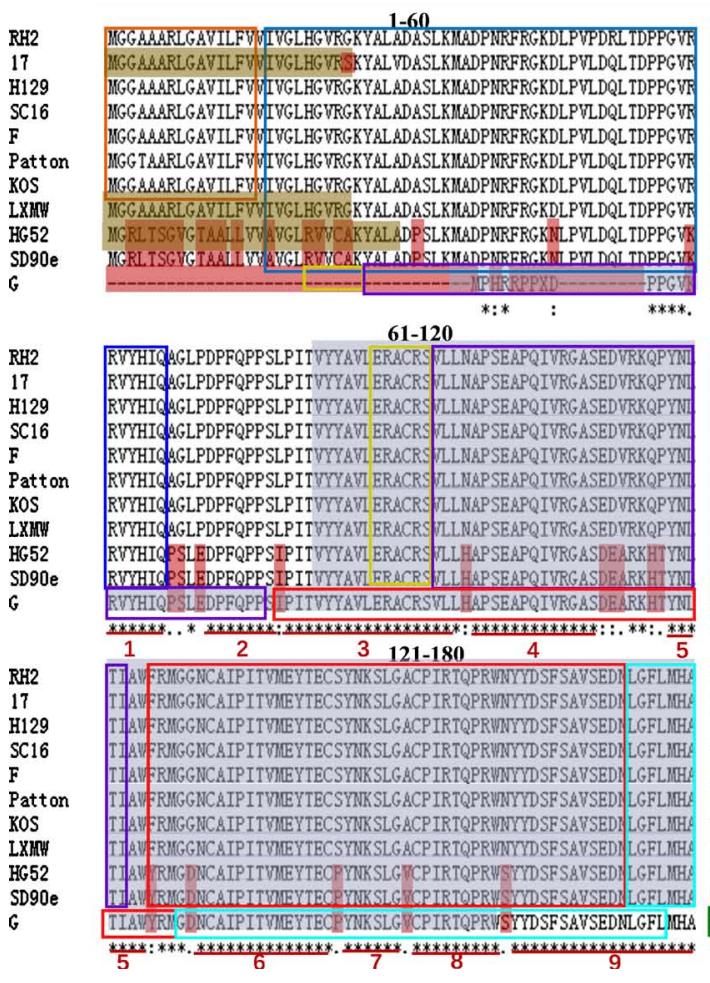

181-240

661-394

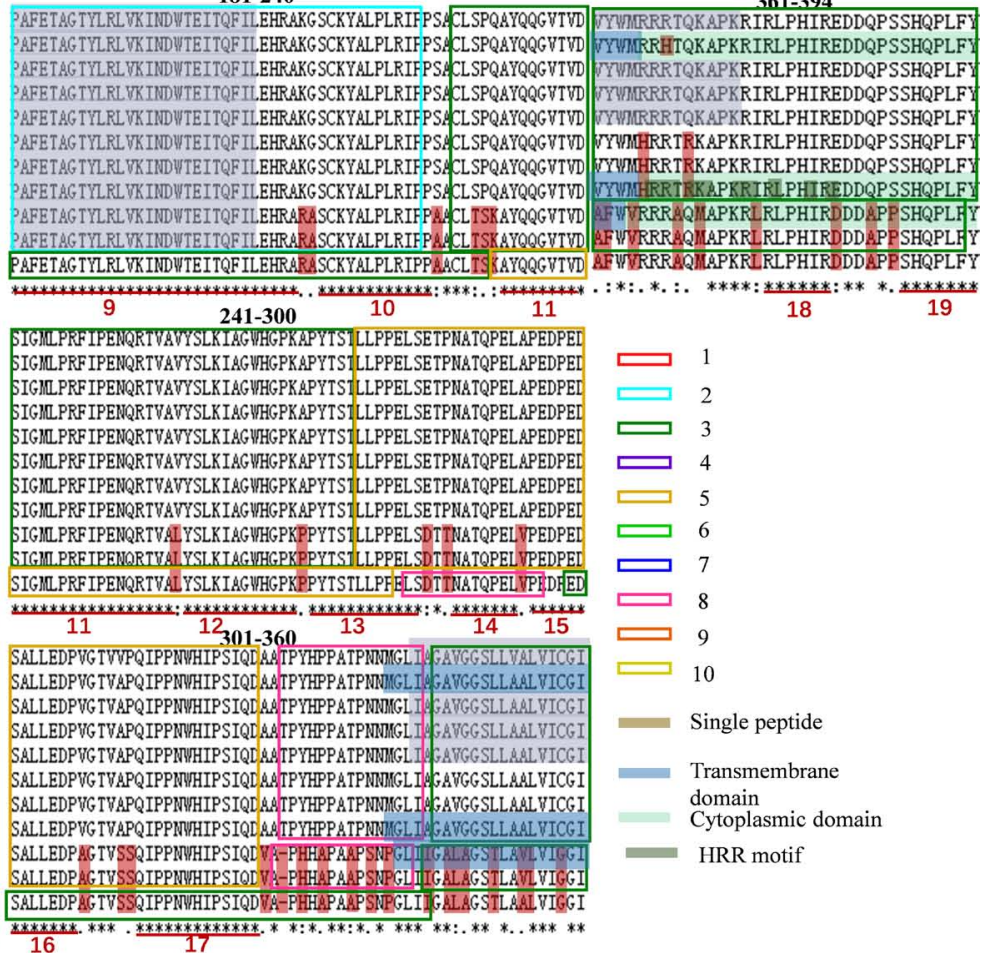

Figure 3. The amino acid sequence alignment of gD.

strains RH2, H129, SC16 and F, and all the HSV-2 strains (black boxes in Figure 3).

The conserved domains among all the gD amino acids of $11 \mathrm{HSV}$ are marked as numbers 1 - 19 and underlined in red and the variable amino acids are marked as numbers $1-8$ underlined in black. The conserved domains predicted by NCBI software are marked in gray. The motifs predicted by the online software are marked by color boxes.

\subsection{Prediction of the Conserved Domains, Motifs and Secondary Structures in gD}

The conserved domains of HSV predicted by NCBI software.

We used the online NCBI conserved domain database

(https://www.ncbi.nlm.nih.gov/) to predict the conserved domains of the gDs of all the 11 HSVs, and the result is marked in gray (Figure 3). We found that the conserved domain in HSV-1 strains 17, Patton, KOS, LXMW and HSV-2 strain HG52, sd90e are the same (located at AA 82-206), however, the conserved domains in HSV-1 strain H129, RH2, SC16, F are the same (located in AA 82-206 and 343-373), the conserved domain in HSV-2 strain G is located in AA 36-106.

\subsection{The Prediction of gD Function Domains}

To predict the function domains of $\mathrm{gD}$, we used online software Phobius (https://phobius.sbc.su.se/). We found that the gD function domains of HSV-1 strain 17 and LXMW are the same (Figure 4). The signal peptide is located at 


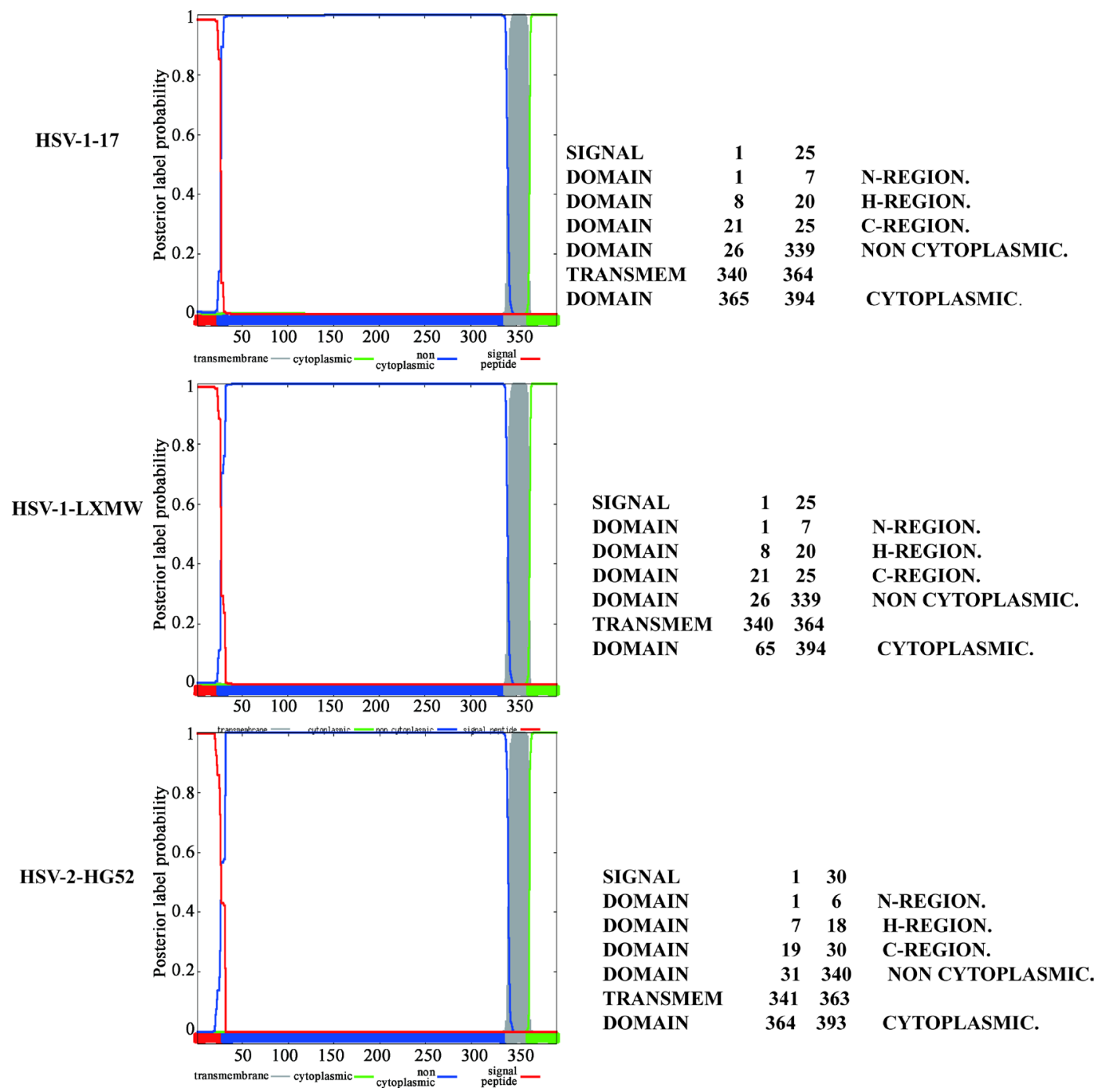

Figure 4. The gD function domains of HSV-1 strains 17 and LXMW, and HSV-2 strain HG52 were predicted by the online software.

AA1-25, the non-cytoplasmic domain located in AA26-339, and the transmembrane domain is located at AA 340-364, and the cytoplasmic domain is located at aa 365-394 (Figure 4). The gD function domains in HSV-2 strain HG52 are as follows: The signal peptide is located at AA 1-30, the non-cytoplasmic domain is located at AA 31-340, the transmembrane domain is located at AA 341-363, and the cytoplasmic domain is located at AA 364-393 (Figure 4). The results are also shown in Figure 3. The mutation at AA 25 is located in the signal peptide domain and all the other 3 mutation sites in HSV-1 are located in the cytoplasmic domain.

\subsection{The Prediction of $10 \mathrm{gD}$ Motifs}

To predict the gD motifs, we used the online software MEME

(http://meme-suite.org/). The motif amino acids are marked in Figure 5(A) and the predicted new motifs are named as 1-10 in Figure 5(B). The results showed 


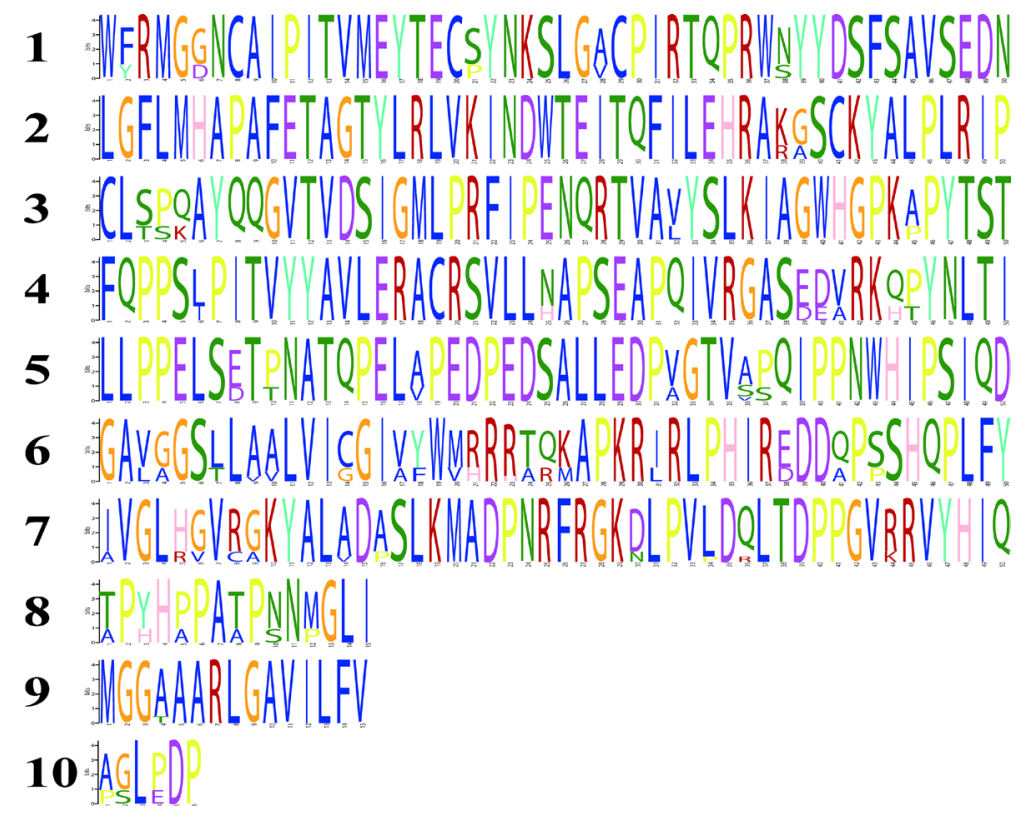

(A)
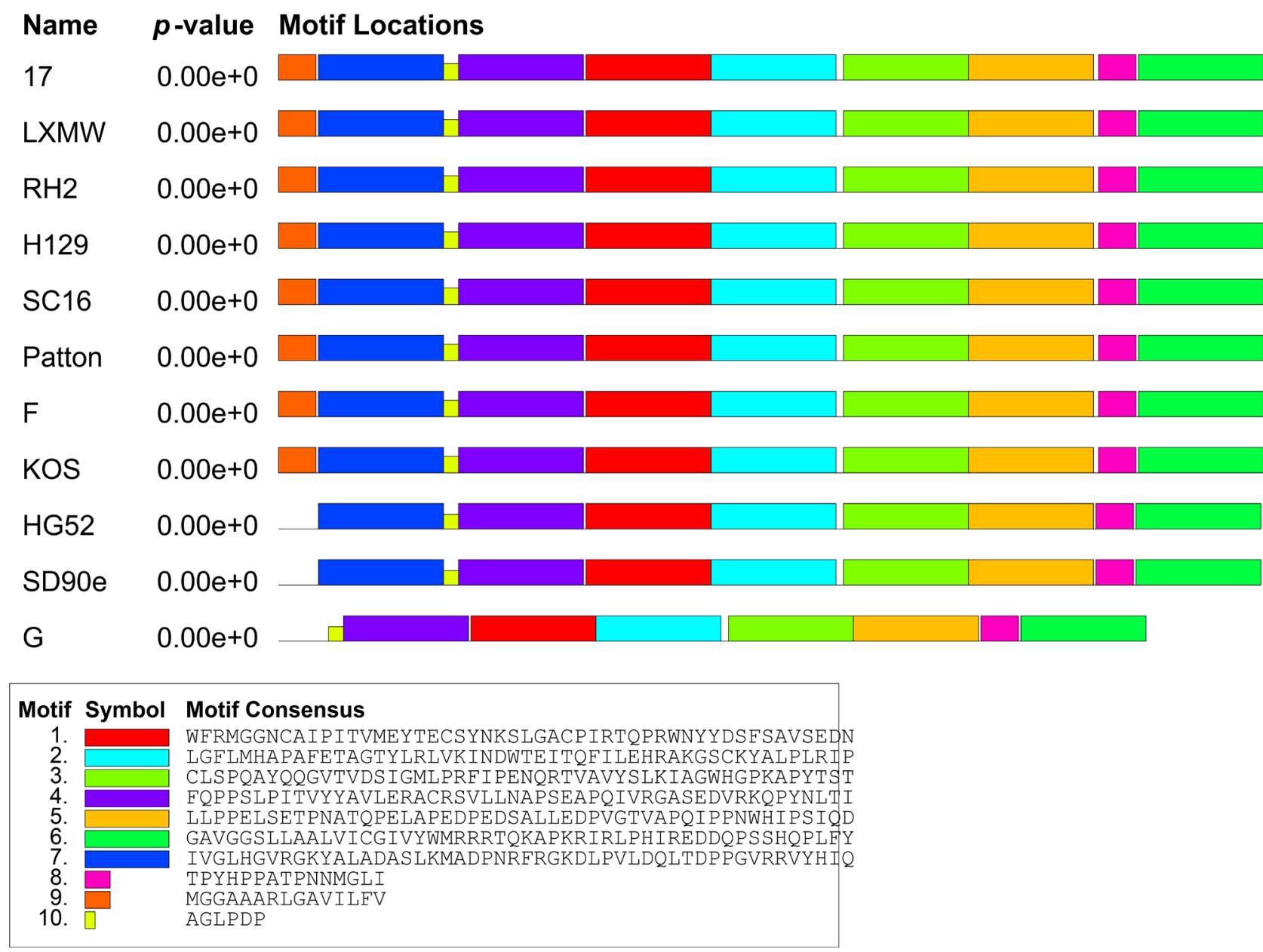

(B)

Figure 5. (A) The predicted consensus sequences of the 10 motifs in gD of $11 \mathrm{HSV}$ strains; (B) The position of predicted 10 motifs in $\mathrm{gD}$ of $11 \mathrm{HSV}$ strains. 
that the motifs of $\mathrm{gD}$ in $7 \mathrm{HSV}-1$ strains 17, H129, RH2, SC16, Patton, KOS, and LXMW are the same. HSV-2 strains HG52 and SD90e have the same motifs. The main motif differences between HSV-1 and HSV-2 are located in the motifs 8 and 9. The motifs of $\mathrm{gD}$ in HSV-2 strain $\mathrm{G}$ is different from any others. All the HSV-2 gD lack the motif 9 that is located in the signal peptide of AA 1-15 (Figure 3 and Figure 5). The HSV stain G also lacks the motif 7 that is located in the receptor binding region. The motif 8 in strains HG52 and SD90e is located at AA 328-342 and the motif 8 in HSV-1 is located at AA 329-343. The motif 8 is near to the transmembrane domain and overlapped with the pro-fusion domain located at AA 250/260-310 (AA 275/285-335 in the alignment in Figure 3) [54]. The motif 5 is also located in the profusion domain. In addition, all the gDs in HSV-2 lack the AA 329 in the motif 8. Most of the gD amino acid mutations between HSV-1 and HSV-2 are located in the variable regions 1, 6 and 7, which overlapped respectively with the signal peptide and transmembrane domains, and with motifs 9, 8 and 6 (Figure 3 and Figure 5).

\subsection{The Prediction of gD Secondary Structures}

We predicted the gD secondary structures of HSV-1 strain 17, LXMW, and HSV-2 strain HG52 using the online software UCL-CS Bioinformatics

(http://bioinf.cs.ucl.ac.uk/). The prediction results are shown in Figure 6. According to the results in HSV-1 strain 17, AA 327-337 form disordered protein binding sites, while in HSV-1 strain LXMW, this site locates at AA 327-338. Both 2 sites are located in the pro-fusion domain and the motif 8 .

\subsection{The gD-Engineered oHSVs}

We summarize the oHSV engineered on the gD to retarget the HSVs to cancer cells (Figure 1(B) and Table 2). Zhou et al. first engineered gD to retarget to the IL13 $\alpha 2$ receptor (IL13R $\alpha 2$ ) and the viruses can enter cells via the IL13R $\alpha 2$ receptor [23]. Then Kamiyama et al. engineered the gD in HSV-1 to retarget to the urokinase plaminogen activator receptor (UPAR) using the same strategy [55]. However, both the engineered HSVs R5111 and R5181 are keeping the ability to bind to the HVEM and nectin-1 [23] [55]. Guoying Zhou et al. engineered HSVs to retarget to the UPAR, named R5322 and R5141, which cannot bind with HVEM/nectin-1 any more [43] [50]. Menotti et al. constructed an oHSV R-LM113 by replacing the AA 6-38 with single-chain antibody ( $\mathrm{scFv}$ ) to HER2 (human epidermal growth factor receptor 2) [56]. Laura Menotti engineered oHSV to retarget to HER2, named R-LM249, in which AA 61-218 were replaced by scFv to HER2 [57]. Shibata et al. explored the oHSV retargeted to the epithelial cell adhesion molecule (EpCAM) [58]. oHSV retargeted to the human epidermal growth factor receptor (EGFR) or human carcinoembryonic antigen (CEA) also have been explored [59]. Most of the engineering was done in the motif 7. We first compared the relationship of engineering sites in $\mathrm{gD}$ with conserved regions, domains and motifs. 
20

30

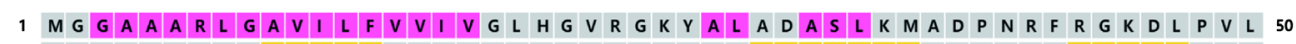

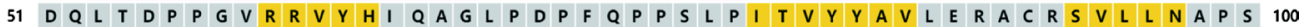

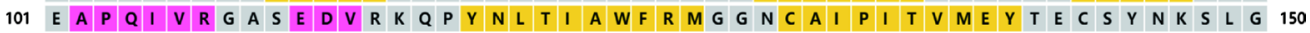
151 A C P P I R T Q Q P R W N Y Y D S F F S A V S E E D N L G F L M H A P A F E E T A G T Y L R L 201 I T Q F I L E H R A K G S C K Y A L P L R I P P S A C L S P Q A Y Q Q G V T V V D S I G M L P R F I P 250

\section{HSV-1-LXMW}

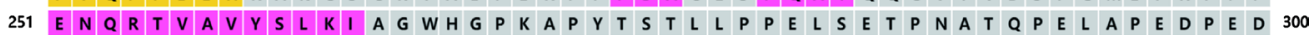

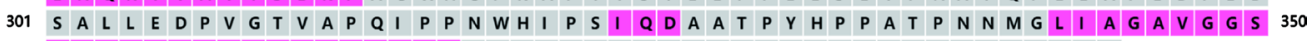

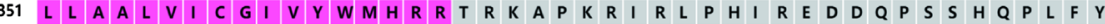$$
10
$$$$
20
$$$$
30
$$$$
40
$$

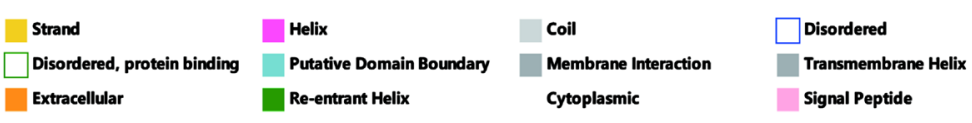

10

30

40

50

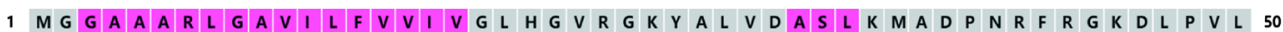
51 D Q L T D P P G V R R V Y H I Q A G L P D P F Q P P S L P I T V Y Y A V L E R A C R S V L L N A P S 100 101 E A 151 A C P P I R T Q P R W N Y Y D S F S A V S E E D N L G F L L H A P A F E E T A G T Y L R L V K I N D W T E 200

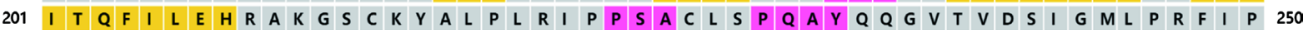

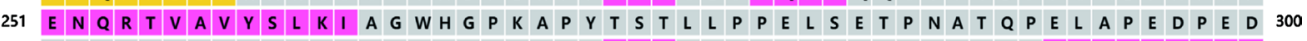

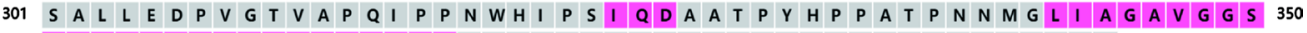

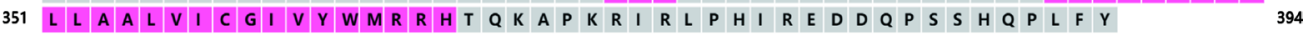
10

20

30

40

50

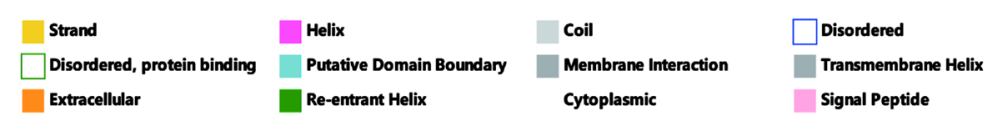

20

30

40

50

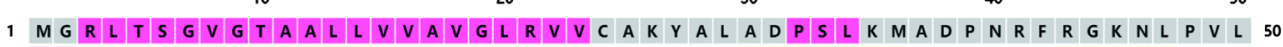

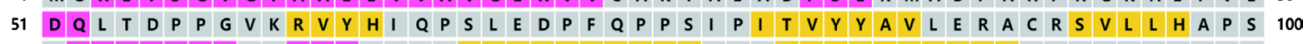

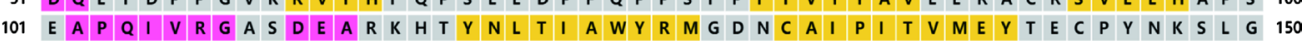

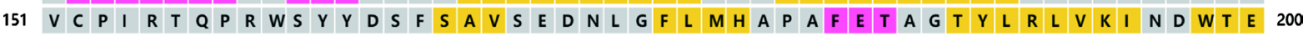

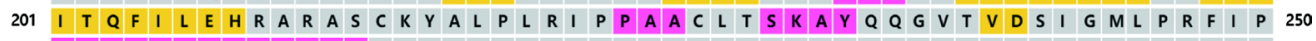

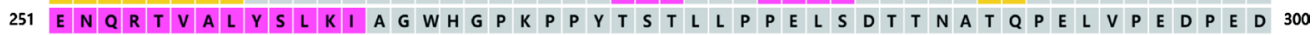

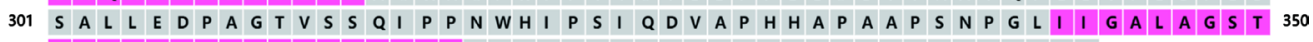

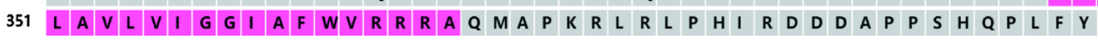

10 30

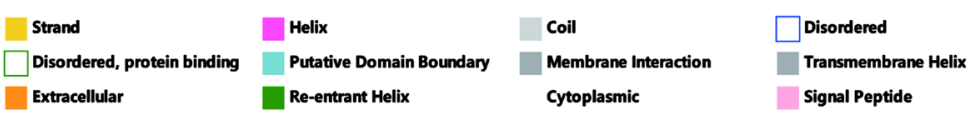

Figure 6. The predicted gD secondary structures of HSV-1 strain 17 and LXMW, and HSV-2 strain HG52.

\section{Discussion}

Studies on HSV gD molecular biology will aid future development of more effective and safer oHSVs. In this article, for the first time, we did systematic comparative sequence analysis of gDs from 8 HSV-1 and 3 HSV-2 strains, including our recently isolated new strain HSV-1-LXMW. These comparisons include phylogenetic analysis, aminoet acid sequence alignment, prediction of functional domains, motifs and secondary structures, and reported oHSVs. We identified 19 conserved regions, 8 variable regions and 10 new motifs in HSV gD and correlated the $\mathrm{gD}$ engineering sites with the newly identified motifs, for the first time. These findings have important implications on HSV gD biology and making better oHSVs.

The phylogenetic analysis showed that the gD amino acid sequence in HSV-1LXMW isolated in China is close to HSV-1 strains Patton and KOS in USA, while our earlier study showed ICP27 is close to HSV-1 strains Patton and H129 
Table 2. oHSV engineered in gD.

\begin{tabular}{|c|c|c|c|c|c|c|c|c|c|}
\hline $\begin{array}{l}\text { Virus } \\
(\mathrm{HSV}-1)\end{array}$ & Name & Receptor & $\begin{array}{l}\text { Detargeted } \\
\text { from } \\
\text { HVEM/ } \\
\text { nectin-1 }\end{array}$ & $\begin{array}{l}\text { Mutations in gD } \\
\text { (corresponding } \\
\text { sites in Figure } 3 \text { ) }\end{array}$ & $\begin{array}{l}\text { Conserved } \\
\text { region in } \\
\mathrm{gD}\end{array}$ & $\begin{array}{l}\text { Functional } \\
\text { domain in } \\
\mathrm{gD}\end{array}$ & $\begin{array}{l}\text { Motif } \\
\text { in } g D\end{array}$ & $\begin{array}{l}\text { Additional } \\
\text { modification }\end{array}$ & Ref \\
\hline Strain 17 & R5111 & IL13R $\alpha 2$ & - & $\begin{array}{l}\text { gD: IL-13 inserted } \\
\text { after AA24 (AA49) }\end{array}$ & None & $\begin{array}{l}\text { Non- } \\
\text { cytoplasmic } \\
\text { domain }\end{array}$ & 7 & $\begin{array}{l}\mathrm{gC}_{\Delta 136-152:} \mathrm{IL}-13 \\
\text { replaced AA148; } \\
\mathrm{gB}_{\Delta 68-77}\end{array}$ & [23] \\
\hline Strain F & R5141 & IL13R $\alpha 2$ & + & $\begin{array}{l}\text { gD: Replaced aa } \\
\text { 1-32 with } \\
\text { IL-13(25-57) }\end{array}$ & None & $\begin{array}{l}\text { Non- } \\
\text { cytoplasmic } \\
\text { domain }\end{array}$ & 7 & $\begin{array}{l}\text { gB: } \operatorname{Poly}(\mathrm{K}) \text { deletion } \\
\text { gC: replaced the aa } \\
1-132 \text { with IL-13 }\end{array}$ & [43] \\
\hline Strain F & $\mathrm{R} 5181$ & uPAR & - & $\begin{array}{l}\text { gD: uPA inserted } \\
\text { between AA } 24 \text { and } \\
25 \text { (AA49 and } \\
\text { AA50) }\end{array}$ & None & $\begin{array}{l}\text { Non- } \\
\text { cytoplasmic } \\
\text { domain }\end{array}$ & 7 & $\begin{array}{l}\text { gC: N-terminal } \\
\text { domain of } \\
\text { gC was replaced with } \\
\text { IL-13 } \\
\mathrm{gB}_{\triangle 68-77}\end{array}$ & [55] \\
\hline Strain F & R5322 & uPAR & + & $\begin{array}{l}\mathrm{gD} \Delta 1-32 \\
\text { mutations at } \mathrm{AA} 34, \\
38,215,222, \\
\text { and } 223 \text { in } \mathrm{gD}, \\
62-218 \text { deletion } \\
\text { (gD } \Delta 25-57, \\
\text { mutation at } \\
\text { AA } 59,63 \text {, } \\
240,247 \\
\text { and } 248 \text { in } \\
\text { gD, } 87-243 \\
\text { deletion) }\end{array}$ & 1, 3-11 & $\begin{array}{l}\text { Non- } \\
\text { cytoplasmic } \\
\text { domain }\end{array}$ & $\begin{array}{l}1,2,4 \\
6,7\end{array}$ & None & [50] \\
\hline $\begin{array}{l}\text { Not } \\
\text { mentioned }\end{array}$ & R-LM113 & HER2 & + & $\begin{array}{l}\text { gD: replaced the } \\
\text { AA 6-38 with scFv } \\
\text { to HER2 (AA31-63) }\end{array}$ & 1 & $\begin{array}{l}\text { Non- } \\
\text { cytoplasmic } \\
\text { domain }\end{array}$ & 7 & None & [56] \\
\hline $\begin{array}{l}\text { Not } \\
\text { mentioned }\end{array}$ & R-LM249 & HER2 & + & $\begin{array}{l}\text { gD: Replaced the } \\
\text { AA 61-218 with } \\
\text { scFv to HER2 } \\
\text { (AA86-243) }\end{array}$ & $3-11$ & $\begin{array}{l}\text { Non- } \\
\text { cytoplasmic } \\
\text { domain }\end{array}$ & $\begin{array}{l}1,2,4, \\
6\end{array}$ & None & [57] \\
\hline Strain KOS & KGNEp & EpCAM & + & $\begin{array}{l}\text { gD: Replaced the } \\
\text { AA } 2-24 \text { with scFv } \\
\text { to EpCAM } \\
\text { (AA27-49) }\end{array}$ & None & $\begin{array}{l}\text { Non- } \\
\text { cytoplasmic } \\
\text { domain }\end{array}$ & 7 & $\begin{array}{l}\text { gB: a hyperactive } \\
\text { allele, D285N/A549T } \\
(\mathrm{gB}: \mathrm{NT}) .\end{array}$ & [58] \\
\hline Strain KOS & $\begin{array}{l}\text { KNE } \\
\text { (retargeted } \\
\text { to EGFR) } \\
\text { KNC } \\
\text { (retargeted } \\
\text { to CEA) }\end{array}$ & $\begin{array}{l}\text { EGFR } \\
\text { CEA }\end{array}$ & + & $\begin{array}{l}\text { gD: Replaced the } \\
\text { AA 2-24 with scFv } \\
\text { to EGFR or CEA, } \\
\text { and introduced the } \\
\text { Y38C to ablate } \\
\text { responsiveness } \\
\text { to nectin-1. } \\
\text { (AA27-49) }\end{array}$ & None & $\begin{array}{l}\text { Non- } \\
\text { cytoplasmic } \\
\text { domain }\end{array}$ & 7 & $\begin{array}{l}\text { gB: D285N/A549T } \\
\text { (gB:NT). }\end{array}$ & [59] \\
\hline
\end{tabular}


[53]. This suggests that our strain is revolutionarily closer to strain Patton. Our identified relatively conserved arginine cluster (RRR residues 365-367) in the cytoplasmic domain was reported to be required for the efficient induction of plasma membrane projection and viral final envelopment, a function important to the viral replication and cell-cell spread [60]. Our literature search identified only one study, which reported that the putative HSV gD domains, motifs or their functions [60]. The only one such article reported that the putative cholesterol-binding motif that overlaps HRR is not essential for the gBsyn phenotype and cell-to-cell spread in HSV-1 strain KOS [61]. Future studies may focus on the functional analysis of our newly identified HSV gD domains and motifs.

Our phylogenetic analysis showed a mean distance of approximately $87 \%$ among the strains tested collectively. An earlier study reported that the gDs of HSV-1 and HSV-2 show 82\% distinctiveness, and are supposed to be similar in structure and function [36]. Several studies have further indicated that the gDs of HSV-1 and HSV-2 have similar affinities for nectin-1 and are interchangeable in virus infection and soluble gD entry inhibition [51] [62] [63]. A report showed that the HSV-2 subunit vaccine containing gD can provide protection in HSV-1 genital infections but not preventing HSV-2 infection [64]. The authors suggest that this phenomenon probably is caused by the $89 \% \mathrm{gD}$ amino acids homology from HSV-1 and -2 [64]. Among the gD receptors, nectin-1 plays a more important role in the process of HSV-2 infection at least in murine models [65] [66]. Although we still cannot find any reports about engineering the $\mathrm{gD}$ in HSV-2 to retarget the virus to cancer cells, there are some reports about oHSV-2 [67] [68] [69]. HSV-2 is reported to have more potent ability to destroy tumor cells, more potent virulence in causing necrotizing stromal keratitis, encephalitis, and produce higher titers in animal models [70]. Future engineering of HSV-2 gD may be pursued.

\section{Conclusions}

The ideal route of delivery of oHSV is systemic route, but the production of neutralization antibody limits this application [52] [71]. The intralesional injection of oHSV limits oHSV usage in clinics. To improve oHSV vectors, we can engineer the epitopes in $\mathrm{gD}$ to reduce the production of neutralization antibody [71]. In addition, engineered oHSVs can enter only the cancer cells, but the clinical usage grade viruses should be produced in normal cells. gD can be engineered to retarget to two different receptors, so that the virus can enter both cancer and special normal cells [72].

Through the understanding of HSV gD, we can engineer the gD to detarget from normal cells and retarget to cancer cells more precisely and efficiently, in order to make better oHSVs.

\section{Author Contributions}

Author contribution: Conceived and designed the experiments: BXR, XQL, 
YYW, HWX. Performed the experiments: XQL, YYW, YNL, HYX, XCP, YX. Analyzed the data and prepared figures: XQL, YYW, XWW. Wrote the manuscript: BXR, XQL, YYW, YNL, HYX, XCP, YX, XWW, HWX.

\section{Funding}

This work was partly supported by grants from the National Natural Science Foundation of China (81872412 to XHW, 81772223 to RBX, 81602303 to XY, 31700736 to WXW). We thank Hubei Province Natural Science Foundation of China (2016CFB180 to WXW), Foundation of Health and Family Planning Commission of Hubei Province (WJ2016Y07 to WXW), Hubei Province Scientific and Technological Research Project (Q20171306 to XWW), Jingzhou Science and Technology Development Planning Project (JZKJ15063 to WXW).

\section{Ethics Statement}

The studies involving human participants were reviewed and approved by Yangtze University. The patients/participants provided their written informed consent to participate in this study.

\section{Conflicts of Interest}

No conflict of interest exists in the submission of this manuscript, and manuscript is approved by all authors for publication. I would like to declare on behalf of my co-authors that the work described was original research that has not been published previously, and not under consideration for publication elsewhere, in whole or in part. All the authors listed have approved the manuscript that is enclosed.

\section{References}

[1] Xin, H.W., et al. (2016) Liver Label Retaining Cancer Cells Are Relatively Resistant to the Reported Anti-Cancer Stem Cell Drug Metformin. Journal of Cancer, 7, 1142-1151. https://doi.org/10.7150/jca.10047

[2] Xin, H.W., et al. (2013) Wnt and the Cancer Niche: Paracrine Interactions with Gastrointestinal Cancer Cells Undergoing Asymmetric Cell Division. Journal of Cancer, 4, 447-457. https://doi.org/10.7150/jca.6896

[3] Xin, H.W., et al. (2013) Label-Retaining Liver Cancer Cells Are Relatively Resistant to Sorafenib. Gut, 62, 1777-1786. https://doi.org/10.1136/gutjnl-2012-303261

[4] Xin, H.W., et al. (2012) Tumor-Initiating Label-Retaining Cancer Cells in Human Gastrointestinal Cancers Undergo Asymmetric Cell Division. Stem Cells, 30, 591-598. https://doi.org/10.1002/stem.1061

[5] Hari, D., et al. (2011) Isolation of Live Label-Retaining Cells and Cells Undergoing Asymmetric Cell Division via Nonrandom Chromosomal Cosegregation from $\mathrm{Hu}-$ man Cancers. Stem Cells and Development, 20, 1649-1658. https://doi.org/10.1089/scd.2010.0455

[6] Liu, Y., et al. (2017) CD44+ Fibroblasts Increases Breast Cancer Cell Survival and Drug Resistance via IGF2BP3-CD44-IGF2 Signalling. Journal of Cellular and Molecular Medicine, 21, 1979-1988. https://doi.org/10.1111/jcmm.13118 
[7] Galdiero, S., et al. (2013) Peptide Inhibitors against Herpes Simplex Virus Infections. Journal of Peptide Science, 19, 148-158. https://doi.org/10.1002/psc.2489

[8] Wang, D., et al. (2018) CRISPR/Cas9 Genome Editing Technology Significantly Accelerated Herpes Simplex Virus Research. Cancer Gene Therapy, 25, 93-105. https://doi.org/10.1038/s41417-018-0016-3

[9] Wu, Z.J., et al. (2018) Oncolytic Viruses for Tumor Precision Imaging and Radiotherapy. Human Gene Therapy, 29, 204-222. https://doi.org/10.1089/hum.2017.189

[10] Zhang, W., et al. (2016) Tumor-Selective Replication Herpes Simplex Virus-Based Technology Significantly Improves Clinical Detection and Prognostication of Viable Circulating Tumor Cells. Oncotarget, 7, 39768-39783.

https://doi.org/10.18632/oncotarget.9465

[11] Fu, X. and Zhang, X. (2002) Potent Systemic Antitumor Activity from an Oncolytic Herpes Simplex Virus of Syncytial Phenotype. Cancer Research, 62, 2306-2312.

[12] Watanabe, D. and Goshima, F. (2018) Oncolytic Virotherapy by HSV. In: Kawaguchi, Y., Mori, Y. and Kimura, H., Eds., Advances in Experimental Medicine and Biology, Vol. 1045, Springer, Singapore, 63-84.

https://doi.org/10.1007/978-981-10-7230-7 4

[13] Pol, J., Kroemer, G. and Galluzzi, L. (2016) First Oncolytic Virus Approved for Melanoma Immunotherapy. Oncoimmunology, 5, e1115641. https://doi.org/10.1080/2162402X.2015.1115641

[14] Agarwalla, P.K. and Aghi, M.K. (2012) Oncolytic Herpes Simplex Virus Engineering and Preparation. In: Kirn, D., Liu, TC. and Thorne, S., Eds., Oncolytic Viruses. Methods in Molecular Biology (Methods and Protocols), Vol. 797, Humana, Totowa, NJ, 1-19. https://doi.org/10.1007/978-1-61779-340-0 1

[15] Liu, B.L., et al. (2003) ICP34.5 Deleted Herpes Simplex Virus with Enhanced Oncolytic, Immune Stimulating, and Anti-Tumour Properties. Gene Therapy, 10, 292-303. https://doi.org/10.1038/sj.gt.3301885

[16] Andtbacka, R.H., et al. (2015) Talimogene Laherparepvec Improves Durable Response Rate in Patients with Advanced Melanoma. Journal of Clinical Oncology, 33, 2780-2788. https://doi.org/10.1200/JCO.2014.58.3377

[17] Pyles, R.B., et al. (1997) A Novel Multiply-Mutated HSV-1 Strain for the Treatment of Human Brain Tumors. Human Gene Therapy, 8, 533-544.

https://doi.org/10.1089/hum.1997.8.5-533

[18] Rampling, R., et al. (2000) Toxicity Evaluation of Replication-Competent Herpes Simplex Virus (ICP 34.5 Null Mutant 1716) in Patients with Recurrent Malignant Glioma. Gene Therapy, 7, 859-866. https://doi.org/10.1038/sj.gt.3301184

[19] Aravind, A., et al. (2012) AS1411 Aptamer Tagged PLGA-Lecithin-PEG Nanoparticles for Tumor Cell Targeting And Drug Delivery. Biotechnology and Bioengineering, 109, 2920-2931. https://doi.org/10.1002/bit.24558

[20] Lin, E. and Nemunaitis, J. (2004) Oncolytic Viral Therapies. Cancer Gene Therapy, 11, 643-664. https://doi.org/10.1038/sj.cgt.7700733

[21] Jeeninga, R.E., Jan, B., van den Berg, H. and Berkhout, B. (2006) Construction of Doxycyline-Dependent Mini-HIV-1 Variants for the Development of a Virotherapy against Leukemias. Retrovirology, 3, Article No. 64.

https://doi.org/10.1186/1742-4690-3-64

[22] Schneider, U., Bullough, F., Vongpunsawad, S., Russell, S.J. and Cattaneo, R. (2000) Recombinant Measles Viruses Efficiently Entering Cells through Targeted Receptors. Journal of Virology, 74, 9928-9936. 
https://doi.org/10.1128/JVI.74.21.9928-9936.2000

[23] Zhou, G., Ye, G.-J., Debinski, W. and Roizman, B. (2002) Engineered Herpes Simplex Virus 1 Is Dependent on IL13Ra2 Receptor for Cell Entry and Independent of Glycoprotein D Receptor Interaction. Proceedings of the National Academy of Sciences of the United States of America, 99, 15124-15129.

https://doi.org/10.1073/pnas.232588699

[24] Kielian, M. and Rey, F.A. (2006) Virus Membrane-Fusion Proteins: More than One Way to Make a Hairpin. Nature Reviews Microbiology, 4, 67-76. https://doi.org/10.1038/nrmicro1326

[25] Forrester, A., Farrell, H., Wilkinson, G., Kaye, J., Davis-Poynter, N. and Minson, T. (1992) Construction and Properties of a Mutant of Herpes Simplex Virus Type 1 with Glycoprotein H Coding Sequences Deleted. Journal of Virology, 66, 341-348. https://doi.org/10.1128/jvi.66.1.341-348.1992

[26] Cai, W.H., Gu, B. and Person, S. (1988) Role of Glycoprotein B of Herpes Simplex Virus Type 1 in Viral Entry and Cell Fusion. Journal of Virology, 62, 2596-2604. https://doi.org/10.1128/jvi.62.8.2596-2604.1988

[27] Roop, C., Hutchinson, L. and Johnson, D.C. (1993) A Mutant Herpes Simplex Virus Type 1 Unable to Express Glycoprotein L Cannot Enter Cells, and Its Particles Lack Glycoprotein H. Journal of Virology, 67, 2285-2297. https://doi.org/10.1128/jvi.67.4.2285-2297.1993

[28] Turner, A., Bruun, B., Minson, T. and Browne, H. (1998) Glycoproteins gB, gD, and gHgL of Herpes Simplex Virus Type 1 Are Necessary and Sufficient to Mediate Membrane Fusion in a Cos Cell Transfection System. Journal of Virology, 72, 873-875. https://doi.org/10.1128/JVI.72.1.873-875.1998

[29] Montgomery, R.I., Warner, M.S., Lum, B.J. and Spear, P.G. (1996) Herpes Simplex Virus-1 Entry into Cells Mediated by a Novel Member of the TNF/NGF Receptor Family. Cell, 87, 427-436. https://doi.org/10.1016/S0092-8674(00)81363-X

[30] Cocchi, F., Menotti, L., Mirandola, P., Lopez, M. and Campadelli-Fiume, G. (1998) The Ectodomain of a Novel Member of the Immunoglobulin Subfamily Related to the Poliovirus Receptor Has the Attributes of a Bona Fide Receptor for Herpes Simplex Virus Types 1 and 2 in Human Cells. Journal of Virology, 72, 9992-10002. https://doi.org/10.1128/JVI.72.12.9992-10002.1998

[31] Geraghty, R.J., Krummenacher, C., Cohen, G.H., Eisenberg, R.J. and Spear, P.G. (1998) Entry of Alphaherpesviruses Mediated by Poliovirus Receptor-Related Protein 1 and Poliovirus Receptor. Science, 280, 1618-1620.

https://doi.org/10.1126/science.280.5369.1618

[32] Warner, M.S., et al. (1998) A Cell Surface Protein with Herpesvirus Entry Activity (HveB) Confers Susceptibility to Infection by Mutants of Herpes Simplex Virus Type 1, Herpes Simplex Virus Type 2, and Pseudorabies Virus. Virology, 246, 179-189. https://doi.org/10.1006/viro.1998.9218

[33] Lopez, M., Menotti, L., Avitabile, E., Dubreuil, P. and Campadelli-Fiume, G. (2000) Nectin $2 \alpha$ (PRR2 $\alpha$ or HveB) and Nectin $2 \delta$ Are Low-Efficiency Mediators for Entry of Herpes Simplex Virus Mutants Carrying the Leu25Pro Substitution in Glycoprotein D. Journal of Virology, 74, 1267-1274.

https://doi.org/10.1128/JVI.74.3.1267-1274.2000

[34] Shukla, D., et al. (1999) A Novel Role for 3-O-Sulfated Heparan Sulfate in Herpes Simplex Virus 1 Entry. Cell, 99, 13-22.

https://doi.org/10.1016/S0092-8674(00)80058-6

[35] Connolly, S.A., Jackson, J.O., Jardetzky, T.S. and Longnecker, R. (2011) Fusing 
Structure and Function: A Structural View of the Herpesvirus Entry Machinery. Nature Reviews Microbiology, 9, 369-381. https://doi.org/10.1038/nrmicro2548

[36] Spear, P.G., Manoj, S., Yoon, M., Jogger, C.R., Zago, A. and Myscofski, D. (2006) Different Receptors Binding to Distinct Interfaces on Herpes Simplex Virus gD Can Trigger Events Leading to Cell Fusion and Viral Entry. Virology, 344, 17-24. https://doi.org/10.1016/j.virol.2005.09.016

[37] Chouljenko, D.V., et al. (2012) Functional Hierarchy of Herpes Simplex Virus 1 Viral Glycoproteins in Cytoplasmic Virion Envelopment and Egress. Journal of Virology, 86, 4262-4270. https://doi.org/10.1128/JVI.06766-11

[38] Feenstra, V., Hodaie, M. and Johnson, D.C. (1990) Deletions in Herpes Simplex Virus Glycoprotein D Define Nonessential and Essential Domains. Journal of Virology, 64, 2096-2102. https://doi.org/10.1128/jvi.64.5.2096-2102.1990

[39] Campadelli-Fiume, G., et al. (2007) The Multipartite System That Mediates Entry of Herpes Simplex Virus into the Cell. Reviews in Medical Virology, 17, 313-326. https://doi.org/10.1002/rmv.546

[40] Carfi, A., et al. (2001) Herpes Simplex Virus Glycoprotein D Bound to the Human Receptor HveA. Molecular Cell, 8, 169-179. https://doi.org/10.1016/S1097-2765(01)00298-2

[41] Connolly, S.A., et al. (2005) Potential Nectin-1 Binding Site on Herpes Simplex Virus Glycoprotein D. Journal of Virology, 79, 1282-1295.

https://doi.org/10.1128/JVI.79.2.1282-1295.2005

[42] Manoj, S., Jogger, C.R., Myscofski, D., Yoon, M. and Spear, P.G. (2004) Mutations in Herpes Simplex Virus Glycoprotein D That Prevent Cell Entry via Nectins and Alter Cell Tropism. Proceedings of the National Academy of Sciences of the United States of America, 101, 12414-12421. https://doi.org/10.1073/pnas.0404211101

[43] Zhou, G. and Roizman, B. (2006) Construction and Properties of a Herpes Simplex virus 1 Designed to Enter Cells Solely via the IL-13a2 Receptor. Proceedings of the National Academy of Sciences of the United States of America, 103, 5508-5513. https://doi.org/10.1073/pnas.0601258103

[44] Fusco, D., Forghieri, C. and Campadelli-Fiume, G. (2005) The Pro-Fusion Domain of Herpes Simplex Virus Glycoprotein D (gD) Interacts with the gD N Terminus and Is Displaced by Soluble Forms of Viral Receptors. Proceedings of the National Academy of Sciences of the United States of America, 102, 9323-9328. https://doi.org/10.1073/pnas.0503907102

[45] Yoon, M., Zago, A., Shukla, D. and Spear, P.G. (2003) Mutations in the N Termini of Herpes Simplex Virus Type 1 and 2 gDs Alter Functional Interactions with the Entry/Fusion Receptors HVEM, Nectin-2, and 3-O-Sulfated Heparan Sulfate but Not with Nectin-1. Journal of Virology, 77, 9221-9231. https://doi.org/10.1128/JVI.77.17.9221-9231.2003

[46] Connolly, S.A., et al. (2002) Structure-Based Analysis of the Herpes Simplex Virus Glycoprotein D Binding Site Present on Herpesvirus Entry Mediator HveA (HVEM). Journal of Virology, 76, 10894-10904. https://doi.org/10.1128/JVI.76.21.10894-10904.2002

[47] Milne, R.S., et al. (2003) Function of Herpes Simplex Virus Type 1 gD Mutants with Different Receptor-Binding Affinities in Virus Entry and Fusion. Journal of Virology, 77, 8962-8972. https://doi.org/10.1128/JVI.77.16.8962-8972.2003

[48] Zhou, G., Avitabile, E., Campadelli-Fiume, G. and Roizman, B. (2003) The Domains of Glycoprotein D Required to Block Apoptosis Induced by Herpes Simplex Virus 1 Are Largely Distinct from Those Involved in Cell-Cell Fusion and Binding to Nec- 
tin1. Journal of Virology, 77, 3759-3767.

https://doi.org/10.1128/JVI.77.6.3759-3767.2003

[49] Krummenacher, C., et al. (2005) Structure of Unliganded HSV gD Reveals a Mechanism for Receptor-Mediated Activation of Virus Entry. The EMBO Journal, 24, 4144-4153. https://doi.org/10.1038/sj.emboj.7600875

[50] Zhou, G. and Roizman, B. (2007) Separation of Receptor-Binding and Profusogenic Domains of Glycoprotein D of Herpes Simplex Virus 1 into Distinct Interacting Proteins. Proceedings of the National Academy of Sciences of the United States of America, 104, 4142-4146. https://doi.org/10.1073/pnas.0611565104

[51] Krummenacher, C., et al. (1998) Herpes Simplex Virus Glycoprotein D Can Bind to Poliovirus Receptor-Related Protein 1 or Herpesvirus Entry Mediator, Two Structurally Unrelated Mediators of Virus Entry. Journal of Virology, 72, 7064-7074. https://doi.org/10.1128/JVI.72.9.7064-7074.1998

[52] Coffin, R.S. (2015) From Virotherapy to Oncolytic Immunotherapy: Where Are We Now? Current Opinion in Virology, 13, 93-100. https://doi.org/10.1016/j.coviro.2015.06.005

[53] Wang, Y.Y., et al. (2019) Identification of Putative UL54 (ICP27) Transcription Regulatory Sequences Binding to Oct-1, v-Myb, Pax-6 and Hairy in Herpes Simplex Viruses. Journal of Cancer, 10, 430-440. https://doi.org/10.7150/jca.29787

[54] Cocchi, F., et al. (2004) The Soluble Ectodomain of Herpes Simplex Virus gD Contains a Membrane-Proximal Pro-Fusion Domain and Suffices to Mediate Virus Entry. Proceedings of the National Academy of Sciences of the United States of America, 101, 7445-7450. https://doi.org/10.1073/pnas.0401883101

[55] Kamiyama, H., Zhou, G. and Roizman, B. (2006) Herpes Simplex Virus 1 Recombinant Virions Exhibiting the Amino Terminal Fragment of Urokinase-Type Plasminogen Activator Can Enter Cells via the Cognate Receptor. Gene Therapy, 13, 621-629. https://doi.org/10.1038/sj.gt.3302685

[56] Menotti, L., Cerretani, A., Hengel, H. and Campadelli-Fiume, G. (2008) Construction of a Fully Retargeted Herpes Simplex Virus 1 Recombinant Capable of Entering Cells Solely via Human Epidermal Growth Factor Receptor 2. Journal of Virology, 82, 10153-10161. https://doi.org/10.1128/JVI.01133-08

[57] Menotti, L., et al. (2009) Inhibition of Human Tumor Growth in Mice by an Oncolytic Herpes Simplex Virus Designed to Target Solely HER-2-Positive Cells. Proceedings of the National Academy of Sciences of the United States of America, 106, 9039-9044. https://doi.org/10.1073/pnas.0812268106

[58] Shibata, T., et al. (2016) Development of an Oncolytic HSV Vector Fully Retargeted Specifically to Cellular EpCAM for Virus Entry and Cell-to-Cell Spread. Gene Therapy, 23, 479-488. https://doi.org/10.1038/gt.2016.17

[59] Uchida, H., et al. (2013) Effective Treatment of an Orthotopic Xenograft Model of Human Glioblastoma Using an EGFR-Retargeted Oncolytic Herpes Simplex Virus. Molecular Therapy, 21, 561-569. https://doi.org/10.1038/mt.2012.211

[60] Arii, J., Shindo, K., Koyanagi, N., Kato, A. and Kawaguchi, Y. (2016) Multiple Roles of the Cytoplasmic Domain of Herpes Simplex Virus 1 Envelope Glycoprotein D in Infected Cells. Journal of Virology, 90, 10170-10181. https://doi.org/10.1128/JVI.01396-16

[61] Carmichael, J.C., et al. (2019) Glycoprotein D of HSV-1 Is Dependent on Tegument Protein UL16 for Packaging and Contains a Motif That Is Differentially Required for Syncytia Formation. Virology, 527, 64-76.

https://doi.org/10.1016/j.virol.2018.09.018 
[62] Muggeridge, M.I., Wilcox, W.C., Cohen, G.H. and Eisenberg, R.J. (1990) Identification of a Site on Herpes Simplex Virus Type 1 Glycoprotein D That Is Essential for Infectivity. Journal of Virology, 64, 3617-3626.

https://doi.org/10.1128/jvi.64.8.3617-3626.1990

[63] Nicola, A.V., Peng, C., Lou, H., Cohen, G.H. and Eisenberg, R.J. (1997) Antigenic Structure of Soluble Herpes Simplex Virus (HSV) Glycoprotein D Correlates with Inhibition of HSV Infection. Journal of Virology, 71, 2940-2946.

https://doi.org/10.1128/jvi.71.4.2940-2946.1997

[64] Belshe, R.B., et al. (2012) Efficacy Results of a Trial of a Herpes Simplex Vaccine. The New England Journal of Medicine, 366, 34-43. https://doi.org/10.1056/NEJMoa1103151

[65] Taylor, J.M., et al. (2007) Alternative Entry Receptors for Herpes Simplex Virus and Their Roles in Disease. Cell Host \& Microbe, 2, 19-28. https://doi.org/10.1016/j.chom.2007.06.005

[66] Kopp, S.J., et al. (2009) Infection of Neurons and Encephalitis after Intracranial Inoculation of Herpes Simplex Virus Requires the Entry Receptor Nectin-1. Proceedings of the National Academy of Sciences of the United States of America, 106, 17916-17920. https://doi.org/10.1073/pnas.0908892106

[67] Wang, Y., et al. (2018) Stability and Anti-Tumor Effect of Oncolytic Herpes Simplex Virus Type 2. Oncotarget, 9, 24672-24683. https://doi.org/10.18632/oncotarget.25122

[68] Yin, L., Zhao, C., Han, J., Li, Z., Zhen, Y., Xiao, R., Xu, Z. and Sun, Y. (2017) Antitumor Effects of Oncolytic Herpes Simplex Virus Type 2 against Colorectal Cancer in Vitro and in Vivo. Therapeutics and Clinical Risk Management, 13, 117-130. https://doi.org/10.2147/TCRM.S128575

[69] Zhao, Q., et al. (2014) A Novel Oncolytic Herpes Simplex Virus Type 2 Has Potent Anti-Tumor Activity. PLOS ONE, 9, e93103. https://doi.org/10.1371/journal.pone.0093103

[70] Fu, X., Tao, L. and Zhang, X. (2007) An Oncolytic Virus Derived from Type 2 Herpes Simplex Virus Has Potent Therapeutic Effect against Metastatic Ovarian Cancer. Cancer Gene Therapy, 14, 480-487. https://doi.org/10.1038/sj.cgt.7701033

[71] Liu, X.Q., et al. (2018) Oncolytic Herpes Simplex Virus Tumor Targeting and Neutralization Escape by Engineering Viral Envelope Glycoproteins. Drug Delivery, 25, 1950-1962. https://doi.org/10.1080/10717544.2018.1534895

[72] Leoni, V., Petrovic, B., Gianni, T., Gatta, V. and Campadelli-Fiume, G. (2018) Simultaneous Insertion of Two Ligands in $\mathrm{gD}$ for Cultivation of Oncolytic Herpes Simplex Viruses in Noncancer Cells and Retargeting to Cancer Receptors. Journal of Virology, 92, e02132-17. https://doi.org/10.1128/JVI.02132-17 


\section{Abbreviations}

oHSV Oncolytic herpes simplex virus

HSV Herpes simplex virus

gD Glycoprotein D

AA Amino acids

OV Oncolytic virus

T-ALL T-cell acute lymphoblastic leukemia $T$

GM-CSF Granulocyte macrophage colony-stimulating factor

PFD Pro-fusion domain

uPAR Urokinase plaminogen activator receptor

scFv Single-chain antibody

CEA Carcinoembryonic antigen

EGFR Epidermal growth factor receptor

HIV-1 Human immunodeficiency virus 1

ALL T-cell acute lymphoblastic leukemia

FDA Food and Drug Administration

HVEM Herpes virus entry mediator

3-OS HS 3-O-sulfated heparan sulfate 